Results: 74 patients, $63.5 \%$ males, aged mean(SD) 54.8 (14.0) years.

56 peripheral PsA and 18 mixed (peripheral predominance); with mean 94.9 (92.4) months of disease; $35.1 \%$ with previous clinical enthesitis and $37.8 \%$ previous dactylitis. Cutaneous disease consisted mainly (82.4\%) in plaque psoriasis, $9.5 \%$ affecting folds, $4.1 \%$ onychopathy.

$52.7 \%$ have received a previous DMARD of (31.1\% MTX, 9.5\% leflunomide) and $23.0 \%$ PUVA; $4.1 \%$ have received previous biological treatment.

Current treatment: $83.8 \%$ DMARDs (68.9\% MTX and $5.4 \%$ leflunomide) with a mean follow-up of 60.6 (55.0) months.

Disease activity:

Skin plaque psoriasis was mainly controlled: $73.4 \%$ low PASI level (23.4\% moderate) median PASI 3.0 [1.5-5.0]; 50.0\% mild BSA, median BSA 3.0 [1.0-6.0] $73.1 \% \mathrm{PGA}$ of very mild or mild-moderate disease

$87.0 \%$ of patients met DAPSA criteria of remission-low disease activity (DAPSA median 3.15 [1.34-6.71]; 55.9\% achieved DAPSA $<4$ ); 75.7\% were in low activity/ remission according to medical judgement.

Overall $63.9 \%$ of patients achieved MDA.

$15.3 \%$ (10 patients) had "relative contraindications" to biological therapy (6 cases of recent cancer, $2 \mathrm{HBV}$ infection).

Conclusions: Over half of PsA patients from our multidisciplinary unit achieve low cutaneous and articular disease activity under csDMARDs, mainly Methotrexate. The use of targeted DMARDs such as apremilast in this scenario, before biological therapies, may improve disease outcomes in a subgroup of patients, corresponding with the efficacy shown in different domains of the psoriatic disease. Further research is needed to compare clinical results between csDMARDs and apremilast.

Disclosure of Interest: None declared

DOI: 10.1136/annrheumdis-2018-eular.4880

\section{THU0297 EVALUATION OF CARDIOVASCULAR RISK FACTORS AMONG PATIENTS WITH PSORIASIS, PSORIATIC ARTHRITIS AND PERIPHERAL SPONDYLOARTHRITIS}

M.R. Camacho-Sánchez ${ }^{1},{ }^{1,2}$ C. López-Medina, L. Bautista-Aguilar ${ }^{1,2}$, L. LadehesaPineda ${ }^{1,2}$, L. Pérez-Sánchez ${ }^{1,2}$, I. Gómez-García ${ }^{1,2}$, A.J. Vélez García-Nieto ${ }^{1,3}$, E. Collantes-Estévez ${ }^{1,2}$, M.D. López-Montilla ${ }^{1,2}$. ${ }^{1}$ Universidad de Córdoba; ${ }^{2}$ Rheumatology; ${ }^{3}$ Dermatology, Hospital Universitario Reina Sofía de Córdobal IMBIC, Córdoba, Spain

Background: It is well known that the prevalence of Cardiovascular Risk Factors (CVRF) in patients with Psoriatic Arthritis (PsA) is higher than in the general population ${ }^{1}$. However, there is a lack of studies comparing PsA against Psoriasis without arthritis, and also against peripheral Spondyloarthritis (SpA).

Objectives: a) To compare the prevalence of CVRF among patients with PsA, Psoriasis without arthritis and peripheral SpA without Psoriasis; and b) to evaluate the association between CVRF and the presence of arthritis and/or Psoriasis.

Methods: A cross-sectional, observational and unicenter study in which clinical, analytical and demographic data from 300 patients were analysed. Patients were divided into four groups: PsA, Psoriasis without arthritis, peripheral SpA without Psoriasis and controls. Patients with PsA and peripheral SpA met CASPAR and peripheral ASAS criteria, respectively. Hypertension, Diabetes (T2DM) and Dyslipidemia were evaluated among the four groups by using the chi-square test. In order to evaluate whether CVRF could be explained by the presence of arthritis or Psoriasis, we divided patients (by excluding control groups) in arthritis/no arthritis and Psoriasis/no Psoriasis. Univariate and multivariate logistic regressions adjusted by sex and age were performed in order to determine variables independently associated with the presence of these three CVRF.

Results: Among the 300 patients included in the analysis, 89 (29.7\%), 35 (11.7\%) and 87 (29\%) patients reported Hypertension, T2DM and Dyslipidemia, respectively. Regarding classification, 61 (20.3\%) patients, 100 (33.3\%), 100 $(33.3 \%)$ and 39 (13.0\%) patients were classified as control group, Peripheral SpA without Psoriasis, PsA and Psoriasis without arthritis, respectively. Patients from the control group showed significantly lower prevalence of Hypertension and Dyslipidemia against the other three groups $(p<0.05)$; however, there were no differences between Peripheral SpA group, PsA and Psoriasis without arthritis regarding CVRF.

Patients with arthritis showed similar prevalence of CVRF than those without arthritis, as well as patients with Psoriasis vs. no Psoriasis.

Univariate analysis showed that Hypertension is significantly associated $(p<0.05)$ to AINEs intake [OR $1.79(95 \% \mathrm{Cl} 1.06-2.99)]$ as well as with disease duration [OR $1.02(95 \% \mathrm{Cl} 1.01-1.05)]$; however, the multivariate analysis adjusted by age and sex did not show significant differences. Regarding T2DM and dyslipidemia, the presence of arthritis or Psoriasis was not associated with the development of these comorbidities.

Conclusions: Our data suggest that the prevalence of CVRF among patients with Psoriasis, PsA and peripheral SpA are similar, although it is higher than in the general population. The presence of Hypertension in these patients is associated with the use of NSAIDs; however, greater new studies would be necessary in order to determine specific associations.

\section{REFERENCE:}

[1] Kharaishi M, Aslanov R, Rampakakis E, et al. Prevalence of cardiovascular risk factors in patients with psoriatic arthritis. Clin Rheumatol. 2014;33 (10):1495-500.

Disclosure of Interest: None declared

DOI: 10.1136/annrheumdis-2018-eular.7264

\section{THU0298 PERITENON EXTENSOR TENDON INFLAMMATION, SYNOVITIS AND ENTHESOPATHY IN PSORIATIC ARTHRITIS: WHAT IS THE CONNEXION?}

${ }^{1}$ C. Macía Villa, S. Falcao ${ }^{2}$, H.B. Hammer ${ }^{3}$, M. Gutierrez ${ }^{4}$, E. De Miguel ${ }^{5}$

${ }^{1}$ Rheumatology, Hospital Universitario Severo Ochoa, Madrid, Spain;

${ }^{2}$ Rheumatology, Chronic Diseases Study Center, NOVA Medical School, UNL, HEM. CHLO., Lisboa, Portugal; ${ }^{3}$ Rheumatology, Diakonhjemmet Hospital, Oslo, Norway; ${ }^{4}$ Division of Musculoskeletal and Rheumatic Disorders, Instituto Nacional de Rehabilitación, Mexico, Mexico; ${ }^{5}$ Rheumatology, Hospital Universitario La Paz, Madrid, Spain

Background: Metacarpophalangeal joint (MCPj) swelling in Psoriatic Arthritis (PsA) can be produced both by intra-articular synovitis (IAS) and peritenon extensor tendon inflammation (PTI). This last lesion has been reported as an enthesitislike lesion.

Objectives: To evaluate if PTI is a synovitis or enthesitis related lesion using MASEI (Madrid Sonographic Enthesis Index) to analyse the existence of association with IAS and PTI.

Methods: 27 consecutive non selected PsA patients were included. An expert rheumatologist obtained the US images from the dorsal aspect of 2 nd to 5 th MCP of both hands evaluating IAS and PTI, and also performed the MASEI examination. In addition to the PD item of MASEI (defined as signal in bone profile or intratendon or bursa at the enthesis), PD OMERACT was evaluated as present or absent (defined as signal in the enthesis $\leq 2 \mathrm{~mm}$ to the bone profile). We used a MyLab 70 XVG machine, Esaote, Genova, Italy, with a greyscale (GS) $13 \mathrm{MHz}$ probe and 7.1 MHz power Doppler (PD) frequency, PRF $750 \mathrm{~Hz}$ and 60 Gain. 3$5 \mathrm{~s}$ videos of each $\mathrm{MCPj}$ and enthesis were obtained in transverse and longitudinal views for further reliability analysis. Reliability of IAS and PTI was performed by 5 readers (true US result was the consensus of at least three) and MASEI's reliability was performed by 3 readers (true US result was the consensus of at least two). For reliability analysis, mean Cohen kappa was used for IAS and PTI, and intraclass correlation coefficient (ICC) for MASEI based on a mean-rating three readers, absolute-agreement, two-way mixed effect model. Statistical association between IAS, PTI and MASEI was analysed with T student test. SPSS statistical package version 20 (SPSS Inc, Chicago, IL) was used.

Results: Eighteen patients had PTI PD $(66,7 \%)$, same for SIA PD. Inter-reader reliability for PTI and SIA was 0.685 and 0.680 kappa values respectively. Interreader reliability for MASEI was excellent ICC 0,922 (IC 95\% 0,852-0,962), similar to PD MASEI ICC 0,921 (IC 95\% 0,851-0,962) and PD OMERACT ICC 0.895 (IC 95\% 0,802-0,949). Association data are shown in table 1.

Abstract THU0298 - Table 1. Association between IAS and PTI with MASEI and different PD subgroups.

\begin{tabular}{|c|c|c|c|c|c|c|}
\hline & \multicolumn{2}{|c|}{ PTI } & \multirow{2}{*}{$\begin{array}{c}p \\
\text { value }\end{array}$} & \multicolumn{2}{|c|}{ IAS } & \multirow{2}{*}{$\begin{array}{c}p \\
\text { value }\end{array}$} \\
\hline & Present & Absent & & Present & Absent & \\
\hline Mean MASEI $\pm S D$ & $\begin{array}{c}32,44 \\
\pm 15,62\end{array}$ & $27 \pm 9,33$ & 0270 & $32 \pm 6,16$ & $\begin{array}{l}27,89 \\
\pm 7,72\end{array}$ & 0380 \\
\hline Mean PD MASEI $\pm S D$ & $8 \pm 6$ & $\begin{array}{c}3,67 \\
\pm 3,28\end{array}$ & 0023 & $\begin{array}{c}6,83 \\
\pm 6,15\end{array}$ & $6 \pm 4,5$ & 0694 \\
\hline $\begin{array}{l}\text { Mean PD OMERACT } \\
\pm \text { SD }\end{array}$ & $1,61 \pm 1,33$ & $\begin{array}{r}0,56 \\
\pm 1,01\end{array}$ & 0033 & $\begin{array}{r}1,39 \\
\pm 1,46\end{array}$ & $1 \pm 1$ & 0426 \\
\hline
\end{tabular}

Conclusions: In PsA, IAS at MCPj didn't show any association with enthesitis However, PTI showed a significant statistically association with active enthesitis (PD MASEI and PD OMERACT). This finding reinforces the idea that PTI at MCP level is related with the swelling of the functional enthesis related to the retinacu lum pulley structure.

\section{REFERENCES}

[1] Mc Gonagle D, et al. The concept of a synovio-enthesal complex and its implications for understanding joint inflammation and damage in psoriatic arthritis and beyond. A\&R 2001;56(8):2482-91.

[2] De Miguel E, et al. Validity of enthesis ultrasound assessment in spondyloarthropathy. ARD 2009;68:169-74. 


\section{THU0299 AN INTEGRATED ANALYSIS OF CHANGES IN LIPID LEVELS AND INCIDENCE OF CARDIOVASCULAR EVENTS FOLLOWING TOFACITINIB TREATMENT IN PATIENTS WITH PSORIATIC ARTHRITIS ACROSS PHASE 3 AND LONG-TERM EXTENSION STUDIES}

${ }^{1}$ D.D. Gladman, C. Charles-Schoeman ${ }^{2}$, I.B. Mclnnes ${ }^{3}$, D.J. Veale ${ }^{4}$, B. Thiers ${ }^{5}$ D. Graham ${ }^{6}$, C. Wang ${ }^{6}$, T.V. Jones ${ }^{7}$, R. Wolk ${ }^{6}$, R. DeMasi ${ }^{7}{ }^{1}$ University of Toronto, Toronto Western Hospital, Toronto, ON, Canada; ' ${ }^{2}$ University of California, Los Angeles, CA, USA; ${ }^{3}$ University of Glasgow, Glasgow, UK; ${ }^{4}$ St. Vincent's University Hospital and University College Dublin, Dublin, Ireland; ${ }^{5}$ Medical University of South Carolina, Charleston, SC; ${ }^{6}$ Pfizer Inc, Groton, CT; ${ }^{7}$ Pfizer Inc, Collegeville, $P A, U S A$

Background: Cardiovascular (CV) disease and cardiometabolic syndrome are common comorbidities/causes of mortality in patients (pts) with psoriatic arthritis (PsA). Tofacitinib is an oral JAK inhibitor for the treatment of PsA.

Objectives: To investigate changes in lipid levels and incidence of $C V$ events in pts with PsA treated with tofacitinib in Phase (P) 3 and long-term extension (LTE) studies.

Methods: Data were analysed for pts who received $\geq 1$ dose of tofacitinib 5 or $10 \mathrm{mg}$ BID or placebo (PBO), integrated across $2 \mathrm{P} 3$ studies (OPAL Broaden [12 months (m); NCT01877668, including adalimumab control]; OPAL Beyond [6 m; NCT01882439]) and 1 LTE study (OPAL Balance [data cut-off May 2016; ongoing, database not locked; NCT01976364]). Lipid levels were assessed throughout P3 and LTE studies; this analysis included data from the PBO-controlled period (MO-3) of P3 studies. Blood pressure, hypertension events (standardised MedDRA query [narrow]) and adjudicated (independent/blinded to treatment) major adverse cardiovascular events (MACE) are reported for all pts who received $\geq 1$ dose of tofacitinib (pooled across doses for hypertension and MACE). Incidence rates (IR; pts with events/100 pt-years [PY]) and $95 \% \mathrm{Cl}$ are reported.

Results: Overall, 783 pts (776 PY of tofacitinib exposure) were included in P3 and LTE studies; treatment duration was 1-927 days. After $3 \mathrm{~m}$ of tofacitinib treatment in P3 studies, dose-dependent increases in lipid levels were observed with tofacitinib; minimal changes were observed with PBO, except for triglycerides (figure 1). Concurrent increases in high-density and low-density lipoprotein (HDL/ $\mathrm{LDL}$ ) and no change in the total cholesterol/HDL ratio were shown. Across P3 and LTE studies, no clinically significant changes in mean systolic or diastolic blood pressure were seen to $24 \mathrm{~m}$. Hypertension events were reported in $38(4.9 \%)$ pts: IR 4.93 [95\% Cl 3.49, 6.77]. Of these events, 4 led to pt discontinuation and 2 were serious adverse events. MACE were reported for $3(0.4 \%)$ pts receiving tofacitinib (IR 0.38 [95\% $\mathrm{Cl} 0.08,1.11]$ ) and included sudden cardiac death (57 days of exposure at time of event), myocardial infarction (197 days) and ischaemic stroke (80 days). This is within the range reported in tofacitinib studies in pts with psoriasis (IR 0.24 [0.15, 0.37]; 8,759 PY of exposure) and rheumatoid arthritis (RA) (IR 0.38 [0.30, 0.47]; 21,286 PY of exposure). No dose-dependent effects on blood pressure were apparent.

Figure. Mean \% change from baseline in lipid levels to Month 3 integrated across Phase 3 studies

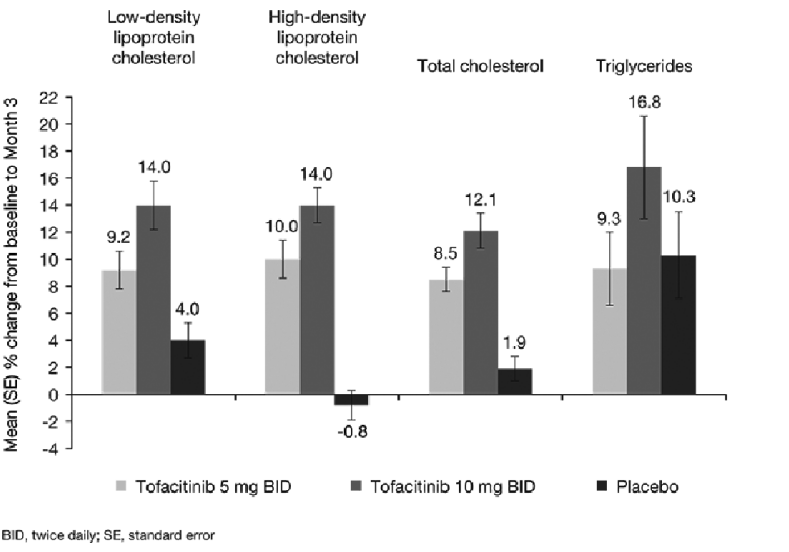

Abstract THU0299 - Figure 1. Mean\% change from baseline in lipid levels to Month 3 integrated across Phase 3 studies. BID, twice daily; SE, standard error
Conclusions: In pts with PsA, the magnitude and dose dependency of increases in lipid levels to M3 were consistent with findings in tofacitinib studies in pts with psoriasis and RA. In P3 and LTE studies, no clinically significant changes were seen in blood pressure or incidence of hypertension. Incidence of MACE was within the range reported in prior tofacitinib studies in psoriasis and RA; however, the long latency of MACE requires longer-term observation.

Acknowledgements: Study sponsored by Pfizer Inc. Medical writing support was provided by A MacLachlan of CMC and funded by Pfizer Inc.

Disclosure of Interest: D. Gladman Grant/research support from: AbbVie, Amgen, Bristol-Myers Squibb, Celgene, Eli Lilly, Janssen, Novartis, Pfizer Inc UCB, Consultant for: AbbVie, Amgen, Bristol-Myers Squibb, Celgene, Eli Lilly, Janssen, Novartis, Pfizer Inc, UCB, C. Charles-Schoeman Grant/research sup port from: AbbVie, Bristol-Myers Squibb, Pfizer Inc, Consultant for: Amgen, Gilead, Pfizer Inc, Regeneron-Sanofi, I. McInnes Grant/research support from: Celgene, Janssen, Novartis, Pfizer Inc, Roche, UCB, Consultant for: AbbVie, Celgene, Janssen, Novartis, Pfizer Inc, Roche, UCB, D. Veale Grant/research sup port from: AbbVie, Actelion, Bristol-Myers Squibb, Janssen, MSD, Novartis, Pfizer Inc, Roche, UCB, Speakers bureau: AbbVie, Actelion, Bristol-Myers Squibb, Janssen, MSD, Novartis, Pfizer Inc, Roche, UCB, B. Thiers Consultant for: Pfizer Inc, Valeant Pharmaceuticals, D. Graham Shareholder of: Pfizer Inc, Employee of: Pfizer Inc, C. Wang Shareholder of: Pfizer Inc, Employee of: Pfizer Inc, T. Jones Shareholder of: Pfizer Inc, Employee of: Pfizer Inc, R. Wolk Shareholder of Pfizer Inc, Employee of: Pfizer Inc, R. DeMasi Shareholder of: Pfizer Inc Employee of: Pfizer Inc

DOI: 10.1136/annrheumdis-2018-eular.1459

\section{THU0300 NETWORK META-ANALYSIS OF TOFACITINIB VS BDMARDS OR APREMILAST FOR THE TREATMENT OF TNF INHIBITOR-NAÏVE PATIENTS WITH PSORIATIC ARTHRITIS}

${ }^{1}$ D.D. Gladman, A.-M. Orbai ${ }^{2}$, J. Gomez-Reino ${ }^{3}$, S. Chang-Douglass ${ }^{4}$ E. Leoncini ${ }^{4}$, H.E. Burton ${ }^{4}$, K.S. Kanik ${ }^{5}$, T. Hendrikx ${ }^{6}$, J.C. Cappelleri', M.-A. Hsu' ${ }^{1}$ University of Toronto, Toronto Western Hospital, Toronto, ON, Canada; ${ }^{2} J o h n s$ Hopkins University School of Medicine, Baltimore, MD, USA $;{ }^{3}$ Hospital Clínico Universitario, Santiago de Compostela, Spain; ${ }^{4}$ Decision Resources Group, London, UK; ${ }^{5}$ Pfizer Inc, Groton, CT; ${ }^{6}$ Pfizer Inc, Collegeville, PA, USA

Background: Tofacitinib is an oral JAK inhibitor for the treatment of psoriatic arthritis (PsA)

Objectives: To perform a systematic literature review (SLR) and network metaanalysis (NMA) to evaluate the efficacy of tofacitinib 5 and $10 \mathrm{mg}$ BID relative to biologic disease-modifying antirheumatic drugs (bDMARDs) or a targeted synthetic DMARD (apremilast [APR]) in tumour necrosis factor inhibitor-naïve (TNFiN) patients with active PsA.

Methods: The SLR identified randomised controlled clinical trials (RCTs) evaluating tofacitinib, bDMARDs or APR to treat patients with active PsA who were TNFiN. Outcomes included American College of Rheumatology (ACR)20 response and change from baseline in Health Assessment Questionnaire-Disability Index $(\Delta \mathrm{HAQ}-\mathrm{DI})$, Dactylitis Severity Score $(\Delta \mathrm{DSS})$ and Leeds Enthesitis Index $(\Delta \mathrm{LEI})$. Treatment effects were only evaluated during placebo (PBO)-controlled trial phases. The Bayesian NMA (with non-informative priors) was conducted using WinBUGs. The binomial logit model was used for ACR20. $\triangle \mathrm{HAQ}$-DI, $\triangle \mathrm{DSS}$ and $\Delta \mathrm{LEl}$ were analysed using the normal identify link model. A fixed-effect model was fitted to the data. Median treatment rankings represent data from each iteration of the model from which inferences are based, following model convergence.

Results: The SLR identified 25 RCTs and 21 were included in the NMA (see treatments in table 1). All trials allowed methotrexate use. PBO-controlled treatment durations ranged from 12-24 weeks. In general, patient characteristics were similar across trials. All treatments were associated with improvements in ACR2O and $\triangle \mathrm{HAQ}$-DI vs PBO. Tofacitinib $5 \mathrm{mg}$ BID was associated with substantially decreased odds ratios (ORs) for ACR20 vs golimumab 50 and $100 \mathrm{mg} \mathrm{Q4W}$, etanercept $25 \mathrm{mg} \mathrm{BW}$, infliximab $5 \mathrm{mg} / \mathrm{kg}$ and secukinumab $150 \mathrm{mg}$ QW-Q4W (table 1); ORs for all remaining comparators were not substantially different. Tofacitinib $10 \mathrm{mg}$ BID was associated with a substantially increased OR for ACR20 vs APR $20 \mathrm{mg}$ BID. Etanercept was associated with an improvement in $\triangle \mathrm{HAQ}$-DI vs tofacitinib 5 and $10 \mathrm{mg}$ BID. There was no difference in $\triangle \mathrm{HAQ}$-DI for tofacitinib vs other bDMARDs. For ACR20, tofacitinib 5 and $10 \mathrm{mg}$ BID were median ranked 14 (95\% credible interval: 8,17$)$ and $9,{ }^{5,14}$ respectively, among 18 comparators. For $\triangle \mathrm{HAQ}-\mathrm{DI}$, tofacitinib 5 and $10 \mathrm{mg}$ BID were median ranked $11^{4,13}$ and $8,{ }^{2,}$ respectively, among 14 comparators. Two studies evaluated $\triangle \mathrm{DSS}$ and $\Delta \mathrm{LEl}$; there were no substantial differences in $\triangle \mathrm{DSS}$ and $\Delta \mathrm{LEI}$ for tofacitinib 5 and $10 \mathrm{mg}$ BID vs adalimumab $40 \mathrm{mg}$ Q2W and ixekizumab $80 \mathrm{mg} \mathrm{Q2W}$ and Q4W. 